\title{
Phrenic Nerve Palsy Related to Birth
}

National Cancer Institute

\section{Source}

National Cancer Institute. Phrenic Nerve Palsy Related to Birth. NCI Thesaurus. Code C116900.

A condition characterized by reduced or absent movement of the ipsilateral diaphragm as a consequence of an injury to the phrenic nerve or its origin in cervical roots 3 through 5 sustained during the birthing process. 